\title{
A Case Report on Focal Placenta Accreta: Successful Conservative Management without Using Methotrexate
}

\author{
(ㄷ) Aslı Tuğçe TEMÜRLENKa, ${ }^{\text {[0 }}$ Adem ÖZDEN ${ }^{a}$

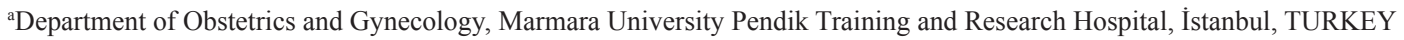

\begin{abstract}
The incidence of the placenta accreta spectrum has gradually increased in recent years due to the increasing number of caesarean deliveries. Likewise, the technique of a conservative approach to these cases is more common. The conservative approach is known to reduce massive blood loss and the amount of hysterectomy performed. Our case was placenta previa-focal accreta, attached to the posterior wall and cervix. During caesarean section, though gently separating the placenta from the edges, invasive part of the placenta was left attached to the uterine wall. In this case, dealing with the retained invasive placental fragments, we aimed to avoid the side effects of methotrexate which has conflicting studies demonstrating the effect in the resorption of postpartum placental tissue. Four months after surgery, the remaining placental tissue was resected by operative hysteroscopy. This approach shows that placenta previa cases with focal accreta areas can be managed successfully by leaving the invasive part of the placental tissue.
\end{abstract}

Keywords: Placenta previa; placenta accrete; methotrexate; rest placenta

Abnormally invasive placenta (AIP) is the abnormal adhesion of the chorionic villi to the myometrium rather than being limited to the decidua basalis. While the definition of placenta increta is used in case of invasion of placenta to myometrium; placenta percreta is used when the placenta invades the serosa and sometimes adjacent organs such as bladder and bowel. Abnormal placental implantation has been detected in $2 \%$ of all singleton births and a 5 -fold increase was shown over the past 3 decades. ${ }^{1}$ The risk for placenta accreta in the presence of placenta previa rises with each subsequent caesarean delivery. Other risk factors include; uterine surgeries, in vitro fertilization, multiparity, maternal age, and even female sex of the infant. Women at the greatest risk of placenta accreta are those who have a previous caesarean delivery with either an anterior or posterior placenta previa overlying the uterine scar. ${ }^{2}$ It was shown that in the presence of a placenta previa, the risk of placenta accreta was $3 \%, 11 \%, 40 \%, 61 \%$, and $67 \%$ for the first, second, third, fourth, and fifth or greater repeat caesarean deliveries, respectively. ${ }^{3}$

With a rate of $38 \%$, placenta accreta is one of the most common causes of peripartum hysterectomy. ${ }^{4}$ Several studies have described conservative management to preserve the uterus such as, surgeries (uterine internal/iliac arterial ligation and balloon tamponade) and methotrexate (MTX) therapy. MTX, a folate antagonist, has been offered as an adjunctive therapy in the conservative management of placenta accrete. ${ }^{5}$ MTX interferences against rapidly dividing cells, like proliferating trophoblast by binding dihydrofolate reductase as a competitive inhibitor. Therefore, it is widely used for the treatment of ectopic pregnancy and gestational trophoblastic disease. However, after delivery, trophoblasts are no longer dividing, thereby

Correspondence: Aslı Tuğçe TEMÜRLENK

Department of Obstetrics and Gynecology, Marmara University Pendik Training and Research Hospital, İstanbul, TURKEY

E-mail: aslitugce1@gmail.com

Peer review under responsibility of Journal of Clinical Obstetrics \& Gynecology. 
MTX is not likely to be effective. The probable cause is that the majority of postpartum cytotrophoblasts are in the G1/G0 phase of the cell cycle. As the proportion of cytotrophoblasts in $\mathrm{S}$ and G2/M phases has been seen to decrease progressively from the $1^{\text {st }}$ trimester to term. ${ }^{6}$

\section{CASE REPORT}

Our patient with placenta previa-focal accreta was gravida 5, para 2 and abortion 3 at the age of 35 . Her last c-section was 1 year ago, having total number of $2 \mathrm{c}$-sections and 3 curettages. Upon detection of placenta previa on the posterior uterine wall during routine follow-up, she was directed to invasive Doppler ultrasonography examination with suspicion of placental invasion. In grayscale ultrasonography, a loss of the normal hypoechoic (clear) retroplacental zone compatible with the appearance of placenta accreta at the lower posterior uterine wall and cervix was monitored. As seen in Figure 1, there were 5 lacunae in these areas which indicates $100 \%$ association with placenta accreta in some studies. ${ }^{7}$ As grayscale ultrasonography is competent to diagnose placenta accreta, with a sensitivity of $77-87 \%$, a specificity of $96-98 \%$, a positive predictive value of $65-93 \%$, and a negative predictive value of $98 \%$, no further imaging needed. ${ }^{8}$ Based on these findings, it was recommended to perform an elective caesarean section at 37 weeks after blood preparation with the pre-diagnosis of local invasion. The patient was informed about possible obstetric complications during and after the procedure and informed consent was obtained.Complete blood count (CBC) of our patient showed; hemoglobin $10.7 \mathrm{~g} / \mathrm{dL}$ and coagulation profile was within normal range. After the preparation of 4 units of red blood cells, a midline vertical incision was performed under general anesthesia. The fetus was delivered via a lower segment transverse incision. Twenty IU of oxytocin in 1 liter of intravenous fluid was started. Both uterine arteries were strangulated with 1-0 Vicryl sutures as a prophylactic procedure. Placenta was gently removed as far as it could, but a focal area did not separate and an intense bleeding started from the areas we were trying to remove. Thereupon, per-operative 2 units of erythrocyte suspension and 1 unit of fresh frozen plasma transfusion were initiated. Leaving some of the abnormal adherent placental tissue in situ, Cho-square stitches were placed on bleeding areas on the posterior wall and cervix. After a Bakri balloon (Bakri Postpartum Balloon,Cook Medical, USA) was placed in the cavity, the incision was double-layer sewn, and the Bakri balloon was filled with $250 \mathrm{cc}$ of saline. Bilateral Pomeroy tubal ligation was made and an active drain was placed in the pouch of Douglas. After making sure that there was no bleeding, the procedure was terminated. $\mathrm{CBC}$ was sent post-operatively which revealed a hemoglobin of $9.2 \mathrm{~g} / \mathrm{dL}$.

The patient was discharged on the postpartum third day in good condition and outpatient clinic check-ups were recommended. Meanwhile, $2 * 375$ mg dose of oral ampicillin/sulbactam were prescribed for 2 weeks. Then discontinued due to the absence of signs of infection in the postpartum check-ups. In ultrasound follow-ups, retained placental fragments of the focal accreta area $25.7 * 19.1 \mathrm{~mm}$ in size were detected (Figure 2). MTX was not administered due to conflicting studies about its benefit and strong side effects. In the postpartum $4^{\text {th }}$ month, the rest placental tissue was resected performing operative hysteroscopy (Figure 3). Afterward, the uterine cavity was observed homogeneous and thin in ultrasonography. Pathology result of the patient was "findings of autolysis and calcification, the findings are compatible with the placental fragment observed". The patient continued her routine gynecological examinations with recovery.

\section{DISCUSSION}

The conservative management has recently become the preferred option in AIP in order to avoid hysterectomy and excessive bleeding at the time of surgery. ${ }^{9}$ It's also a preferred option to preserve fertility and to reduce peripartum hysterectomy-related morbidity. Nevertheless, leaving the placenta in utero after caesarean delivery can lead to complications, such as infection or disseminated intravascular coagulation (DIC). DIC occurs due to increased placental coagulation activity as well as consumption of clotting factors. In a recent systematic review, routinely monitoring of the coagulation parameters is sug- 


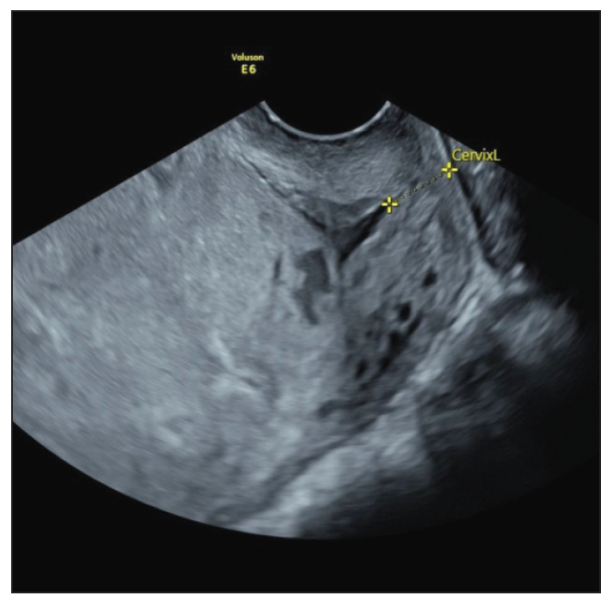

FIGURE 1: Lacunae on posterior wall and cervix.

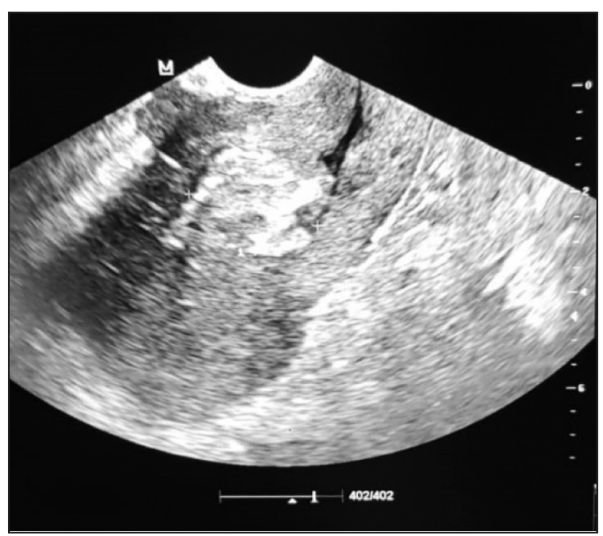

FIGURE 2: Retained placental fragments

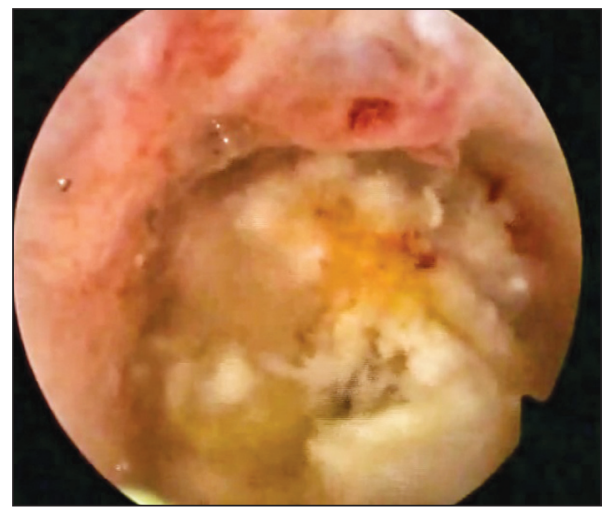

FIGURE 3: Hysteroscopic view of retained placental fragments.

gested to avoid this situation. ${ }^{10}$ In accordance with this, we monitored fibrinogen and D-dimer regularly.

Federation of Gynaecology and Obstetrics guidelines recommend check-up visits with clinical examination, pelvic ultrasound, vaginal swabs and blood tests against the risk of infection. ${ }^{11}$ A French multicenter retrospective study of 167 cases of Placenta Accreta Spectrum (PAS) disorders showed an infection rate of $28.1 \%{ }^{12}$ Accordingly, considering the risk of infection, we performed suitable follow-up and prescribed prophylactic antibiotics in accordance with the guidelines.

PAS cases with the posterior placental location was found to be related to ureteral injury. ${ }^{13}$ In our case, there was such a risk when applying cho-square sutures to bleeding areas at the level of the cervix, but an appearance compatible with hydronephrosis was not detected in postpartum renal ultrasound and it was concluded that there was no ureteral injury.

Additional procedures being worked on are prophylactic ligation of uterine arteries (or internal iliac arteries) and treatment with MTX, an antimetabolite agent. In a review that included 53 articles, all published data on efficacy and safety of MTX therapy was evaluated. ${ }^{14}$ There wasn't enough evidence on its efficacy and safety to support its routine uses in all cases of invasive placenta. In addition, MTX may lead to several common toxicities including nausea, vomiting, diarrhea and mucosal ulcers and some serious side effects such as leukopenia, anemia, gastrointestinal ulcerations, nephrotoxicity, dose-related hepatotoxicity and a rare hypersensitivity like lung reaction. MTX is also contraindicated during breast feeding. ${ }^{15}$ Additionally during the postpartum followup, the use of $\beta$-human chorionic gonadotropin, does not seem to guarantee treatment success or resorption of retained placental tissue. Thereupon, the use of MTX for the postpartum management of placenta accreta is not plausible.

\section{Source of Finance}

During this study, no financial or spiritual support was received neither from any pharmaceutical company that has a direct connection with the research subject, nor from a company that provides or produces medical instruments and materials which may negatively affect the evaluation process of this study.

\section{Conflict of Interest}

No conflicts of interest between the authors and / or family members of the scientific and medical committee members or members of the potential conflicts of interest, counseling, expertise, 
working conditions, share holding and similar situations in any firm.

\section{Authorship Contributions}

Idea/Concept: Asll Tuğçe Temurlenk; Design: Adem Özden; Control/Supervision: Aslı Tuğçe Temurlenk; Data Collection and/or Processing: Aslı Tuğçe Temurlenk, Adem Özden; Analysis and/or Interpretation: Adem Özden; Literature Review: Aslı Tuğçe Temurlenk; Writing the Article: Aslı Tuğçe Temurlenk; Critical Review: Aslı Tuğçe Temurlenk; References and Fundings: Aslı Tuğçe Temurlenk; Materials: Aslı Tuğçe Temurlenk.

\section{REFERENCES}

1. Belfort MA, Shamshirsaz AA, Fox KA. The diagnosis and management of morbidly adherent placenta. Semin Perinatol. 2018;42(1): 49-58. [Crossref] [PubMed]

2. Committee on Obstetric Practice. Committee opinion no. 529: placenta accreta. Obstet Gynecol. 2012;120(1):207-11. [Crossref] [PubMed]

3. Silver RM, Landon MB, Rouse DJ, Leveno KJ, Spong CY, Thom EA, et al; National Institute of Child Health and Human Development Maternal-Fetal Medicine Units Network. Maternal morbidity associated with multiple repeat cesarean deliveries. Obstet Gynecol. 2006; 107(6):1226-32. [Crossref] [PubMed]

4. Knight M; UKOSS. Peripartum hysterectomy in the UK: management and outcomes of the associated haemorrhage. BJOG. 2007; 114(11):1380-7. [Crossref] [PubMed]

5. Doumouchtsis SK, Arulkumaran S. The morbidly adherent placenta: an overview of management options. Acta Obstet Gynecol Scand. 2010;89(9):1126-33. [Crossref] [PubMed]

6. Yan H, Li Z, Yan Z, Li X, Li X, Yu L, et al. Methotrexate induces apoptosis of postpartum placental cytotrophoblasts. Cells Tis- sues Organs. 2017;203(4):231-42. [Crossref] [PubMed]

7. Comstock CH, Love JJ Jr, Bronsteen RA, Lee W, Vettraino IM, Huang RR, et al. Sonographic detection of placenta accreta in the second and third trimesters of pregnancy. $\mathrm{Am} \mathrm{J} \mathrm{Ob-}$ stet Gynecol. 2004;190(4):1135-40. [Crossref] [PubMed]

8. Warshak CR, Eskander R, Hull AD, Scioscia AL, Mattrey RF, Benirschke K, et al. Accuracy of ultrasonography and magnetic resonance imaging in the diagnosis of placenta accreta. Obstet Gynecol. 2006;108(3 Pt 1):573-81. [Crossref] [PubMed]

9. Zhang $\mathrm{C}, \mathrm{Li} \mathrm{H}$, Zuo C, Wang X. Retrospective analysis: Conservative treatment of placenta increta with methotrexate. J Obstet Gynaecol Res. 2018;44(5):907-13. [Crossref] [PubMed]

10. Biele C, Kaufner L, Schwickert A, Nonnenmacher $A$, von Weizsäcker $K$, Muallem MZ, et al. Conservative management of abnormally invasive placenta complicated by local hyperfibrinolysis and beginning disseminated intravascular coagulation. Arch Gynecol Obstet. 2021;303(1):61-8. [Crossref] [PubMed] [PMC]

11. Sentilhes L, Kayem G, Chandraharan E, Palacios-Jaraquemada J, Jauniaux E; FIGO Pla- centa Accreta Diagnosis and Management Expert Consensus Panel. FIGO consensus guidelines on placenta accreta spectrum disorders: Conservative management. Int J Gynaecol Obstet. 2018;140(3):291-8. [Crossref] [PubMed]

12. Sentilhes L, Ambroselli C, Kayem G Provansal M, Fernandez H, Perrotin F, et al. Maternal outcome after conservative treatment of placenta accreta. Obstet Gynecol. 2010;115(3):526-34. [Crossref] [PubMed]

13. Morgan EA, Sidebottom A, Vacquier M, Wunderlich W, Loichinger M. The effect of placental location in cases of placenta accreta spectrum. Am J Obstet Gynecol. 2019;221(4): 357.e1-357.e5. [Crossref] [PubMed]

14. Farasatinasab M, Moghaddas A, DashtiKhadivaki S, Raoofi Z, Nasiripour S. Management of abnormal placenta implantation with methotrexate: a review of published data. Gynecol Obstet Invest. 2016;81(6):481-96. [Crossref] [PubMed]

15. Fox KA, Shamshirsaz AA, Carusi D, Secord $A A$, Lee $P$, Turan OM, et al. Conservative management of morbidly adherent placenta: expert review. Am J Obstet Gynecol. 2015; 213(6):755-60. [Crossref] [PubMed] 